\title{
Erratum to: Histological and morphometric analyses of seasonal testicular variations in the Jungle Crow (Corvus macrorhynchos)
}

Muhammad Nazrul Islam • Xiao Bo Zhu •

Masato Aoyama $\cdot$ Shoei Sugita

Published online: 27 May 2010

(C) Japanese Association of Anatomists 2010

Erratum to: Anat Sci Int

DOI 10.1007/s12565-009-0066-6

The name of the second author should be given as Xiao Bo Zhu, not Ziao Bo Zhu, as originally published.

The online version of the original article can be found under doi:10.1007/s12565-009-0066-6.

M. N. Islam · X. B. Zhu · M. Aoyama · S. Sugita $(\square)$

Department of Animal Science, Faculty of Agriculture,

Utsunomiya University, 350 Minemachi,

Utsunomiya, Tochigi 321-8505, Japan

e-mail: sugita@cc.utsunomiya-u.ac.jp

M. N. Islam

United Graduate School of Agricultural Science,

Tokyo University of Agriculture and Technology,

Tokyo, Japan

Present Address:

X. B. Zhu

Graduate School of Agriculture, The University of Tokyo,

Tokyo, Japan 